\title{
Malos tratos del judío Juce Curi a su mujer Jamila Abenaçoh
}

\author{
Encarnación MARÍN PADILLA \\ CSIC, Madrid
}

Como ya he dicho en alguna ocasión, no es frecuente encontrar en los protocolos notariales del siglo XV noticias que se refieran a peleas y ofensas personales, más o menos íntimas, de miembros de las comunidades judías aragonesas. Estas se solventaban en la propia aljama; quienes ostentaban la autoridad jurídica las dirimían según la ley judía. Sin embargo, cuando dentro de la comunidad no se obtenía solución del conflicto, el ofendido o sus parientes podían recurrir a una autoridad jurídica cristiana de instancia superior.

En el caso que a continuación expongo, se requirió al merino y comisario de las aljamas de judíos y moros de Zaragoza y de la villa de Alagón; en ausencia de este, actuó su lugarteniente.

Los hechos que motivaron el requerimiento con el que se pretendió lograr que el ofensor fuera castigado tuvieron lugar en la aljama judía de la villa de Alagón y comenzaron en torno al mes de agosto de 1444, fecha en la que Juce Curi ${ }^{1}$ contrajo matrimonio con Jamila, hija de Jeuda Abenaçoh.

El «casamiento, si quiere matrimonio» de Juce y Jamila se hizo «segunt ley di jodios», y Jeuda «dio muytos e diversos bienes, joyas e dineros, segunt su facultat ... a la dita su filla en Ayuda del dito su matrimonio ... con el dito Juce e muyto mas».

Una vez casados, Jamila había «servido e estado con el dito Juce ..., marido suyo e servidolo por todo su poder, como muller puede ... ley de jodios». Mientras que Juce,

${ }^{1}$ Este apellido también suele aparecer escrito Çuri. 
con mala voluntat e malquirienca que ha e lieva a la dita Jamila ... e con spiritu diabolico se lexa dir e dize por las plazas e do quiere que ba que la dita Jamila ... no bino birgen a su poder ... e no le basta al dito Juce Curi ferela e machula feridas mortales, assi en tal manera que no es quasi senyora de sus brachos ni de mandar su persona, assi matex la quiere lancar por las fenestras de nueyces e le faze tales feridas que si no por los bezinos que muytas begadas le han acorido, ella seria muerta que no guarda ni si es prenyada ni bueyra e le faze otras injurias muytas e diversas, que de ley de jodios no son di dir ni fazer ni encara sustener, que no guarda si esta mestruosa ni no.

Por si todo ello fuera poco, en «los capitoles del dito matrimonio, feyto e firmado entre» Juce, Jamila y su padre Jeuda Abenaçoh, se había acordado que Juce fuera

tenido de fazer ... procuracion [a su suegro], segunt costa por los pactos e condiciones ... havidos e firmados e con buenos testimonios Roborados e encara mediant juramento y alalma y excomunicacion, segunt ley de jodios, de lo qual el dito Juce no ha quesido Res fazer ni teme la jura ni teme dios ni los judges, ante de dia en dia ... biene acomulando faze mas malas cosas e diversas que son contra ley de jodios.

Jeuda Abenaçoh no estaba dispuesto a tolerar tal situación. Se sentía indignado por el trato que su hija Jamila recibía, porque Juce no le otorgaba el poder y por las calumnias que profería «de tanto tiempo aqua». Además, consideraba que «no son palavras aquestas de buena persona ni fama para el padre ni madre de la dita Jamila ni de sus parientes».

Harto de aguantar insultos y ofensas, y quizás al no sentirse amparado por aquellos de su propia aljama que debían de intervenir y aplicar medidas correctivas pertinentes al caso, Jeuda resolvió recurrir al merino y comisario de las aljamas de judíos y moros de Zaragoza y de la villa de Alagón, el jurista converso don Juan Roiz. Pero como suele ser habitual en esta clase de procesos, no han llegado a nosotros los distintos pasos del procedimiento jurídico que debió de llevarse a cabo ante la denuncia de Jeuda Abenaçoh contra su yerno Juce Curi, aunque este fue apresado.

Documentalmente sólo nos consta que, el 15 de junio de 1445, en Zaragoza y ante el notario Miguel Navarro, lugarteniente del citado merino, compareció Jeuda Abenaçoh «en aquella millor 
manera que puede e deve se querella contra e adversus Juce Curi, jodio preso»,

e contra qualquiere procurador o procuradores por el en judicio legitimament intervenient o intervenientes. Et querellado en judicio dize e propone dezir e sponer entiende, en lugar de demanda e por demanda, caso que le sea dada licencia de litigar por procurador dizsen e afirmaran contra el, seyer berdat e si negado sera probar entiende, que el ... casó la dita su filla Jamilla, segunt ley de jodios, con el dito Juce Curi ... ha bien diez o onze meses ... e aquesto ys berdat.

A continuación, ante el lugarteniente Miguel Navarro, explicó Jeuda, «e probar entiende si negado sera», el comportamiento de su yerno con su hija Jamila; lo que iba diciendo por las plazas y donde quería, sobre la virginidad de esta; y el desdoro que suponía para Jamila, sus padres y parientes, sus «palavras malas e injuriosas e contra toda berdat e contra ley de jodios e son muy injuriosas a la dita Jamila e a todos sus parientes e no Res menos».

Una vez expuestas las quejas contra su yerno, Jeuda pasó a suplicar

a bos Senyor, lugartenient del merino, que bos placia, por merce buestra, de proveyr de Remedios di justicia, segunt ley de jodios e en aquesto tirarez scandalos, muertes e otros males, los quales se speran a seguir por las ditas razones e injurias por el dito Juce Curi a la dita Jamila e a sus parientes feytas e di qua dia fazer no cessa.

Después de informar también al lugarteniente sobre la negativa de su yerno Juce a darle poder como se pactó en el acuerdo matrimonial, Jeuda volvió a insistir en que

si de remedio de justicia no se provido cerqua aquellas, senyor merino, daqui se speran seguir grandes males e scandalos e tales e semblantes deven seyer castigados e punidos, segunt ley di jodios e a ellos no les deve seyer dada fe ninguna, como aquel que ys crebantador de la jura mayor; e todas aquellas cosas son malas e de mal exenplo e tales que sin castigo no deven pasar.

Al llegar a este punto de su comparecencia, Jeuda demandó y suplicó

que por bos, dito senyor lugartenient de comisario e por buestra sentencia difinitiva, seyer detenido, preso e condempnado a tor- 
nar a la dita Jamila la fama buena que le ha tirado e Restituyr e livrar aquella e no Res menos, seyer judgado e castigado por aquellos remedios que di justicia de ley de jodios fazer se puede e deve e no Res menos, seyer judgado, castigado, permutado, sentenciado e declarado por bos, dito senyor merino, segunt que por ley de jodios se deve fazer.

Jeuda terminó su requerimiento del siguiente modo:

E assi matex bos suplica ..., senyor merino, que como el dito Jeuda sia pobre e miserable persona, que lo remetades a judicio e exhamen de ley de jodios como en la, en aquesta buestra aljama de la ciudat de Caragoca, sia la fuera de los Rabis, Rave e maestros que saben e entienden cómo, en qué manera al jodio se deve haver e castigar e corregir, sus mulleres demandando, seyer assi pronunciado por bos, dito senyor merino, e en otra manera seyer proveydo contra él, segunt que conto e pecunio de los jodios deve proceyr e cerqua lo sobredito, segunt qualquiere de ley di jodios, contra tales e semblantes se debe proveyr, es acostumbrado, demandando seyer Respuesto etc. ${ }^{2}$.

Así puso fin a su comparecencia Jeuda Abenaçoh y así termina la información documental como suele ocurrir en muchos de los requerimientos hechos a merinos y sus lugartenientes. Por tanto se ignora cuál fue la actuación de Miguel Navarro; lo que dijo al respecto el acusado Juce Curi en su defensa, el castigo y las penas que se le impusieron y su posterior comportamiento; y el proceder de las autoridades judías cuando tuvieron noticia del requerimiento de uno de los miembros de su aljama al lugarteniente del merino.

En cuanto a la desgraciada Jamila Abenaçoh, a quien su padre Jeuda entregó «en Ayuda del dito su matrimonio» con Juce «muytos e diversos bienes, joyas e dineros, segunt su facultat ... e muyto mas», su caso recuerda, desgraciadamente, al de la infortunada judía epilense Ceti Leredi ${ }^{3}$.

Después de entregar este articulito para su publicación y siguiendo con mis investigaciones, he encontrado un documento de

2 «Porque si negado sera etc. no escrevient se e alhora dicia e parecia dius guarda ad present salvo jure latius, addendi, minuendi, mutandi e corrigendo etc. e procostatur di expunsis etc.» (Z.APN., Antón de Aldovera, 1445, fols. 1-2v).

${ }^{3}$ E. MARín PADILlA, «Inútil rebeldía de Ceti Leredi en relación con su matrimonio (siglo XV)», Sefarad 52 (1992) págs. 501-512. 
fecha anterior a los hechos comentados, en el que se alude a un Juce Curi y a su hijo neófito.

El lunes 19 de junio de 1424, en Zaragoza, el menestral de la ciudad Gil Guillén recibió del judío de la villa de Alagón Juce Curi, de su hijo Juan de Tania y de la mujer de este, Anastasia Sister, los setenta florines de oro que le debían, según carta pública de comanda hecha en Alagón el 1 de noviembre de 1418, ante el notario de la villa Francés Climent. Gil quiso que la comanda se cancelara y absolvió a los tres y a sus bienes de cualquier petición o demanda, civil o criminal, que pudiera hacerles en el futuro ${ }^{4}$.

De la existencia de este hijo neófito de un Juce Curi podría deducirse que este era viudo cuando se casó con Jamila Abenaçoh; se trataría por tanto de su segundo matrimonio.

\section{RESUMEN}

La autora da noticia de un instrumento público de requerimiento hecho al merino y comisario de las aljamas de judíos y moros de Zaragoza y de la villa de Alagón, ante el notario zaragozano Antón de Aldovera, en 1445. El requeriente, el judío de Alagón Jeuda Abenaçoh, pretendía lograr que se castigara a su yerno Juce Curi por los malos tratos infligidos a su mujer Jamila Abenaçoh, hija de Jeuda.

\section{SUMMARY}

The author makes public a legal injunction presented to the merino and comisario of the Jewish and Moorish aljamas in Zaragoza, including the town of Alagon. It was witnessed by Antón de Aldovera, Zaragoza notary, in 1445. The plaintiff, Jeuda Abenaçoh, of Alagon, was attempting to have his son-in-law Juce Curi punished for mistreating Jeuda's daughter Jamila Abenaçoh, Juda Curi's wife.

\footnotetext{
${ }^{4}$ Z.APN., Pedro Serrano, Prot. 1424, fol. 113v.
} 